\title{
Classification of Myoviridae bacteriophages using protein sequence similarity
}

\author{
Rob Lavigne ${ }^{1}$, Paul Darius ${ }^{1}$, Elizabeth J Summer ${ }^{2}$, Donald Seto ${ }^{3}$, \\ Padmanabhan Mahadevan ${ }^{3}$, Anders S Nilsson ${ }^{4}$, Hans W Ackermann ${ }^{5}$ and \\ Andrew M Kropinski*6,7
}

\begin{abstract}
Address: ${ }^{1}$ Biosystems Department, Katholieke Universiteit Leuven, Kasteelpark Arenberg 21, Leuven, B-3001, Belgium, ${ }^{2}$ Center for Phage Therapeutics, Department of Biochemistry and Biophysics, Texas A\&M University, College Station, TX 77843, USA, ${ }^{3}$ Department of Bioinformatics and Computational Biology, George Mason University, Manassas, VA20110, USA, ${ }^{4}$ Department of Genetics, Microbiology and Toxicology, Stockholm University, S-106 91 Stockholm, Sweden, 5 Felix d'Herelle Reference Center for Bacterial Viruses, Department of Medical Biology, Faculty of Medicine, Laval University, Quebec, QC, G1K 4C6, Canada, ${ }^{6}$ Laboratory for Foodborne Zoonoses, Public Health Agency of Canada, 110 Stone Road West, Guelph, ON, N1G 3W4, Canada and 7Department of Molecular \& Cellular Biology, University of Guelph, Guelph, ON, N1G 2W1, Canada

Email: Rob Lavigne - Rob.Lavigne@biw.kuleuven.be; Paul Darius - paul.darius@biw.kuleuven.be; Elizabeth J Summer - elizsum@tamu.edu; Donald Seto - dseto@gmu.edu; Padmanabhan Mahadevan - pmahadev@gmu.edu; Anders S Nilsson - anders.nilsson@gmt.su.se; Hans W Ackermann - ackermann4@gmail.com; Andrew M Kropinski* - kropinsk@queensu.ca

* Corresponding author
\end{abstract}

Published: 26 October 2009

BMC Microbiology 2009, 9:224 doi:10.1 |86/I47|-2180-9-224

This article is available from: http://www.biomedcentral.com/I47I-2/80/9/224

(C) 2009 Lavigne et al; licensee BioMed Central Ltd.

This is an Open Access article distributed under the terms of the Creative Commons Attribution License (http://creativecommons.org/licenses/by/2.0), which permits unrestricted use, distribution, and reproduction in any medium, provided the original work is properly cited.
Received: 16 January 2009

Accepted: 26 October 2009

\begin{abstract}
Background: We advocate unifying classical and genomic classification of bacteriophages by integration of proteomic data and physicochemical parameters. Our previous application of this approach to the entirely sequenced members of the Podoviridae fully supported the current phage classification of the International Committee on Taxonomy of Viruses (ICTV). It appears that horizontal gene transfer generally does not totally obliterate evolutionary relationships between phages.
\end{abstract}

Results: CoreGenes/CoreExtractor proteome comparison techniques applied to 102 Myoviridae suggest the establishment of three subfamilies (Peduovirinae, Teequatrovirinae, the Spounavirinae) and eight new independent genera (Bcep78I, BcepMu, FelixOI, HAPI, BzxI, PBI, phiCDII9, and phiKZ-like viruses). The Peduovirinae subfamily, derived from the P2-related phages, is composed of two distinct genera: the "P2-like viruses", and the "HPI-like viruses". At present, the more complex Teequatrovirinae subfamily has two genera, the "T4-like" and "KVP40-like viruses". In the genus "T4-like viruses" proper, four groups sharing $>70 \%$ proteins are distinguished: T4-type, 44RR-type, RB43-type, and RB49-type viruses. The Spounavirinae contain the "SPOI-"and "Twortlike viruses."

Conclusion: The hierarchical clustering of these groupings provide biologically significant subdivisions, which are consistent with our previous analysis of the Podoviridae. 


\section{Background}

We recently described methods aimed at unifying classical and genomic classification of bacteriophages by integration of protein sequence data and physicochemical parameters. We developed two protein sequence similarity-based tools, CoreExtractor and CoreGenes [1], to parse-out and quantify relationships between pairs of phages resulting in a single correlation score [2]. This analysis is followed by a deconstruction and literature analysis of the known morphological and physicochemical characteristics of these phages. The biological interpretation of molecular correlations between 55 fully sequenced Podoviridae show that this approach agrees with the current phage classification of the International Committee on Taxonomy of Viruses (ICTV) and suggests that, generally, horizontal gene transfer only partially masks evolutionary relationships between phages. Using a cut-off value of $40 \%$ homologous proteins, we verified relationships between phages known to be similar and identified several new bacteriophage genera. At the 20$30 \%$ homology level, we identified relationships of a higher order justifying the introduction of the subfamily taxonomical category.

The Myoviridae in the VIIIth ICTV Report comprise five genera of bacteriophages $(\mathrm{Mu}, \mathrm{P} 1, \mathrm{P} 2, \mathrm{SPO} 1$, and T4-like viruses) and one genus of archeal viruses, phiH. I3 and phiKZ-like phages have been recently proposed as additional genera http://www.ncbi.nlm.nih.gov/ICTVdb/Ictv/ fs myovi.htm. These genera include only a small fraction of presently known myoviruses with fully sequenced genomes [3]. We analyze and interpret here the correlations between 102 Myoviridae genomes found in the National Center for Biotechnology Information (NCBI) and the Tulane University T4 Genome databases.

\section{Results and discussion}

Figure 1 shows the correlation, based on the CoreExtractor distance measure, among all available Myoviridae genomes in the NCBI databases. To verify and more subtly compare individual correlations, the CoreGenes approach was applied to subsets of related phages, including several genomes not currently available in public databases (Table 1). As in previous analyses of the Podoviridae [2], threshold values of $40 \%$ and $20 \%$ (and 0.6 and 0.8 relative dissimilarity, respectively) of homologous proteins strongly suggest genus and subfamily boundaries, respectively (Additional file 1). They are corroborated by morphological, molecular or physiological data and discussed in the paragraphs below.

\section{A. Myoviridae Subfamilies \\ I. Teequatrovirinae \\ I. T4-like viruses nova comb}

The ICTV currently lists only six sequenced viruses as members of the T4 phage genus, namely enterobacterial phage T4, Acinetobacter phage 133, Aeromonas phages Aeh1, 65 and 44RR2.8t, and Vibrio phage nt-1. However, the scientific literature and public databases abound with descriptions of "T4-like" phages and the analysis of complete genome sequences indicates that the T4-related phages constitute one of the largest groups of bacterial viruses. This corroborates ecogenomic studies on the diversity of these viruses as apparent in the heterogeneity of capsid (gp23) genes in isolates from Japanese rice fields [4], marine systems [5,6], and from Lithuania [7], Bangladesh and Switzerland [8]. These studies suggest that the fully sequenced $\mathrm{T} 4$ phages are but a small fraction of the T4-related genomes in nature. Nevertheless, there are clear commonalities among all sequenced "T4-like" genomes from different host groups, including the cyanophages, namely a set of 33-35 genes that have persisted during the evolution of genomes with sizes from 160 to $250 \mathrm{~kb}$ [9]. This core of genes seems to have resisted divergence throughout evolution. Nevertheless, these horizontal substitutions do not erase the evidence of the global relationship between phages and clear hybrid phages within this group have not been identified to date $[10,11]$. Work done at Tulane University $[10,11]$, led to the tentative conclusion that it takes about $33 \mathrm{~T} 4$ genes to determine a genetic program that controls lytic phage development in the host cell.

Based on the Myoviridae cluster dendrogram (Figure 1), the current ICTV genus "T4-like viruses" can be subdivided into two genera and several subgroups. By analogy to the T7-related podoviruses, now named the Autographivirinae, the former ICTV genus was raised to the rank of a subfamily, the Teequatrovirinae, named after the best-studied of these phages, coliphage T4. The first genus, the "T4like viruses", includes what were previously termed the Teven and "pseudo-T-even" phages [12,13]. Our name perpetuates the old ICTV nomenclature, but is now limited to enterobacterial and Aeromonas phages. The KVP40 phages, consisting of two former members of the "schizo-T-evens" [14] form the other genus.

The "T4-like viruses" are morphologically indistinguishable and have moderately elongated heads of about 110 $\mathrm{nm}$ in length, $114 \mathrm{~nm}$ long tails with a collar, base plates with short spikes, and six long kinked tail fibers. Within this assemblage, we identified four distinct subtypes with $>70 \%$ protein similarity. These are the T4-type phages (phages T4, JS10, JS98, RB14, RB32, RB51, RB69), 44RRtype (phages 44RR2.8t, 31, 25), RB43-type (RB43, RB16), and the RB49-type viruses (RB49, JSE, $\phi 1$ ). They can be 
Table I: Comparison of CoreExtractor and CoreGenes and the classification of fully sequenced members of the Myoviridae

\begin{tabular}{|c|c|c|c|}
\hline \multicolumn{4}{|c|}{ I. TEEQUATROVIRINAE } \\
\hline & & & Percent identity \\
\hline I. The T4-like viruses & Accession No. & CoreExtractor & CoreGenes \\
\hline \multicolumn{4}{|l|}{ T4-type phages } \\
\hline Escherichia phage T4 & NC_000866 & 100 & 100.0 \\
\hline Escherichia phage JSIO & NC_01274I & Not determined & 72.7 \\
\hline Escherichia phage JS98 & NC_010105 & 77 & 74.1 \\
\hline Escherichia phage RBI4 & NC_0I 2638 & Not determined & 83.5 \\
\hline Escherichia phage RB32 & NC_0085I5 & 88 & 84.2 \\
\hline Escherichia phage RB5I & NC_012635 & Not determined & 85.6 \\
\hline Escherichia phage RB69 & NC_004928 & 73 & 73.4 \\
\hline \multicolumn{4}{|l|}{ 44RR2.8-type phages } \\
\hline Aeromonas phage 44RR2.8t & NC_005I35 & 100 & 100.0 \\
\hline Escherichia phage 3I & NC_007022 & 98 & 97.6 \\
\hline Aeromonas phage 25 & NC_008208 & 82 & 82.5 \\
\hline \multicolumn{4}{|l|}{ RB43-type phages } \\
\hline Escherichia phage RB43 & NC_007023 & 100 & 100.0 \\
\hline Escherichia phage RBI6 & Tulane & Not determined & 84.2 \\
\hline \multicolumn{4}{|l|}{ RB49-type phages } \\
\hline Escherichia phage RB49 & NC_005066 & 100 & 100.0 \\
\hline Escherichia phage JSE & NC_OI 2740 & Not determined & 93.6 \\
\hline Escherichia phage $\phi \mid$ & NC_00982I & 97 & 97.1 \\
\hline \multicolumn{4}{|l|}{ 2. The KVP40-like viruses } \\
\hline Vibrio phage KVP40 & NC_005083 & 100 & 100.0 \\
\hline Vibrio phage nt-I & Tulane & Not determined & 80.8 \\
\hline Acinetobacter phage 133 & Tulane & Not determined & 39.9 \\
\hline Aeromonas phage Aeh I & NC_005260 & 28 & 35.6 \\
\hline Aeromonas phage 65 & Tulane & Not determined & 34.9 \\
\hline
\end{tabular}

I. The P2-like viruses

Enterobacteria phage P2

Enterobacteria phage $\mathrm{W} \phi$

Yersinia phage L-4I3C

Enterobacteria phage 186

Enterobacteria phage PsP3

Salmonella Fels-2

Salmonella SopE $\phi$

Burkholderia phage $\phi \mathrm{E} 202$

Mannheimia phage $\phi$-MhaAI-PHLIOI

Pseudomonas phage $\phi C T X$

Burkholderia phage $\phi 52237$

Ralstonia phage RSAI

Burkholderia phage $\phi \mathrm{E} \mid 2-2$

2. The HPI-like viruses

Haemophilus phage HPI

Haemophilus phage HP2

Pasteurella phage FI08

Vibrio phage KI39

Vibrio phage $\kappa$

Aeromonas phage $Ф \mathrm{OI} 8 \mathrm{P}$

I. The SPOI-like viruses Bacillus phage SPOI

2. The Twort-like viruses Staphylococcus phage Twort

\section{PEDUOVIRINAE}

NC_001895

NC_005056

NC_004745

NC_001317

NC_005340

NC_010463

AY319521

NC_009234

NC_00820I

NC_003278

NC_007/45

NC_009382

NC_009236

NC_001697

NC_0033I5

NC_008193

NC_003313

NC_010275

NC_009542

$\begin{array}{cc}100 & 100.0 \\ 89 & 90.7 \\ 95 & 88.4 \\ 72 & 74.4 \\ 70 & 72.1 \\ 65 & 67.4\end{array}$

Not determined $\quad 62.8$

$51 \quad 55.8$

$51 \quad 55.8$

$53 \quad 53.5$

$49 \quad 51.2$

$49 \quad 51.2$

$49 \quad 48.8$

$100 \quad 100.0$

$\begin{array}{ll}97 & 85.7\end{array}$

$57 \quad 59.5$

$51 \quad 54.8$

$49 \square 5.8$

$44 \quad 50.0$

\section{SPOUNAVIRINAE}

NC_0I 1421

NC 007021
100

100
100.0

100.0 
Table I: Comparison of CoreExtractor and CoreGenes and the classification of fully sequenced members of the Myoviridae (Continued)

\begin{tabular}{llll}
\hline Staphylococcus phage K & NC_005880 & 74 & 43.5 \\
Staphylococcus phage GI & NC_007066 & 97 & 56.9 \\
Listeria phage PI00 & NC_0076I0 & 51 & 34.8 \\
Listeria phage A5I I & NC_0098II & 51 & 35.4 \\
Peripherally related: & NC_009904 & 32 & 31.8 \\
Enterococcus phage $\phi E C 24 C$ & NC_006565 & 25 & 26.2 \\
\hline
\end{tabular}

I. The Mu-like viruses

OTHER ICTV-RECOGNIZED GENERA

\begin{tabular}{|c|c|c|c|}
\hline Enterobacteria phage Mu & NC_000929 & 100 & 100.0 \\
\hline The PI-like viruses & & & \\
\hline Escherichia phage PI & NC_005856 & 100 & 10 \\
\hline Escherichia phage P7 & AF503408 & Not determined & 87 \\
\hline
\end{tabular}

I. The Bcep78I-like viruses Burkholderia phage Bcep78I Burkholderia phage Bcep43 Burkholderia phage Bcepl Burkholderia phage BcepNY3 Xanthomonas phage OP2

2. The BcepMu-like viruses Burkholderia phage BcepMu Burkholderia phage $\phi E 255$

3. The FelixOI-like viruses Salmonella phage Felix OI Escherichia phage wV8 Erwinia phage $\phi \mathrm{Ea} 2 \mathrm{I}-4$

4. The HAPI-like viruses Halomonas phage $\phi \mathrm{HAP}-\mathrm{I}$ Vibrio phage VP882

5. The Bzxl-like viruses Mycobacterium phage BzxI Mycobacterium phage Catera Mycobacterium phage Cali Mycobacterium phage ScottMcG Mycobacterium phage Rizal Mycobacterium phage Spud Mycobacterium phage Myrna

6. The phiCDI I9-like viruses Clostridium phage $\Phi C D$ I 19 Clostridium phage $\Phi C D 2$ Clostridium phage $\Phi C D 27$

7. The phiKZ-like viruses Pseudomonas phage $\phi K Z$ Pseudomonas phage 20I $\$ 2-1$ Pseudomonas phage EL

8. The PBI-like viruses Pseudomonas phage PBI Pseudomonas phage F8 Pseudomonas phage LBL3 Pseudomonas phage LMA2 Pseudomonas phage SN Pseudomonas phage 14-I Burkholderia phage BcepFI Burkholderia phage BcepBIA

\section{PROPOSED GENERA WITHIN THE MYOVIRIDAE}

NC_004333

NC 005342

NC 005263

NC_009604

NC 007710

NC_005882

NC 009237

NC_005282

EU877232

NC_0118II

NC_010342

NC_009016

NC 004687

NC_008207

NC_01 I27!

NC 011269

NC_0II 272

NC 011270

NC 011273

NC 007917

NC_009231

NC 011398

NC 004629

NC_01082I

Peripherally related:

NC_007623

NC_011810

NC_007810

NC 011165

NC 011166

NC_011756

$\mathrm{NC} 011703$

NC 009015

Peripherally related:

NC 005886

$\begin{array}{ll}100 & 100.0 \\ 98 & 95.5 \\ 85 & 90.9 \\ 87 & 92.4 \\ 52 & 50.0 \\ 100 & 100.0 \\ 89 & 86.8\end{array}$

100

100.0

Not determined $\quad 92.4$

Not determined $\quad 52.7$

$100 \quad 100.0$

Not determined $\quad 73.9$

$100 \quad 100.0$

$95 \quad 95.4$

$92 \quad 93.6$

94.5

$95 \quad 95.9$

$97-98.2$

$39 \quad 46.3$

Not determined $\quad 100.0$

Not determined $\quad 50.6$

Not determined $\quad 36.7$

$100 \quad 100.0$

$50-51.0$

$30 \quad 21.9$

Not determined $\quad 100.0$

Not determined $\quad 95.7$

$97 \quad 89.2$

$97 \quad 95.7$

Not determined $\quad 92.5$

Not determined $\quad 92.5$

$44 \quad 43.0$

$22 \quad 24.7$

PRELIMINARY GROUPINGS AND UNRELATED PHAGES

(cyanomyoviridae)

Synechococcus S-PM2

NC_006820

100

100.0 
Table I: Comparison of CoreExtractor and CoreGenes and the classification of fully sequenced members of the Myoviridae (Continued)

\begin{tabular}{|c|c|c|c|}
\hline Synechococcus Syn9 & NC_008296 & 41 & 41.5 \\
\hline Prochlorococcus phage P-SSM2 & NC_006883 & 35 & 40.3 \\
\hline Prochlorococcus phage P-SSM4 & NC_006884 & 35 & 39.8 \\
\hline \multicolumn{4}{|l|}{ (phage $S f V$ and relatives) } \\
\hline Shigella phage SfV & NC_003444 & 100 & 100.0 \\
\hline Escherichia phage P27 & NC_003356 & 42 & 43.1 \\
\hline Aggregatibacter phage Аaф23 & NC_004827 & 100 & 100.0 \\
\hline Clostridium phage c-st & NC_00758I & 100 & 100.0 \\
\hline Escherichia phage rV5 & NC_0II04I & 100 & 100.0 \\
\hline Escherichia phage P4 & NC_001609 & 100 & 100.0 \\
\hline Escherichia phage $\phi E c o M-G J I$ & NC_0I0I06 & 100 & 100.0 \\
\hline lodobacteriophage phiPLPE & NC_01II42 & 100 & 100.0 \\
\hline Lactobacillus phage Lb338-I & NC_0I 2530 & 100 & 100 \\
\hline Microcystis phage Ma-LMMOI & NC_008562 & 100 & 100.0 \\
\hline Natrialba phage $\phi C h \mathrm{I}$ & NC_004084 & 100 & 100.0 \\
\hline Ralstonia phage RSLI & NC_0108II & 100 & 100.0 \\
\hline Rhodothermus phage RM378 & NC_004735 & 100 & 100.0 \\
\hline Streptococcus phage EJ-I & NC_005294 & 100 & 100.0 \\
\hline Thermus phage $\phi Y S 40$ & NC_008584 & 100 & 100.0 \\
\hline
\end{tabular}

subdivided by the presence of specific encoded proteins as outlined in Table 2. In the subtype T4 phages, three specific proteins with defined functions (Pin, MotB, ModA) were found. Pin is an inhibitor of the host's Lon protease $[15,16]$, while the other two proteins function to modulate transcription $[17,18]$.

Heteroduplex analyses indicate that coliphages T2, T4 and T6 share $>85 \%$ sequence similarity [19], warranting their inclusion, in spite of lack of detailed sequence data for T2 and T6, into the T4-type subgroup. The DNA of the T-even phages contains 5-hydroxymethylcytosine (5-HMC). While this modified nucleotide is common in T4-related phages [20], its presence has not been ascertained biochemically in the other phages (JS98, RB14, RB32, RB69) included in this subgroup. T4 gp42 dCMP hydroxymethylase and Alc that blocks transcription from cytosine containing DNA are required for the incorporation of 5-HMC rather than cytosine into T-even DNA. Genes specifying homologs of the T4 gp42 and Alc proteins are also present in the 44RR2.8t-type phages.

\section{KVP40-like viruses}

The KVP40 viruses comprise two marine vibriophages, KVP40 and nt-1, with genomes of approximately $246 \mathrm{~kb}$. KVP40 infects Vibrio parahaemolytius and was isolated from seawater. Phage nt- 1 infects Vibrio natriegens and originates from a coastal marsh. The phages differ from T4 in head length (137 nm vs. $111 \mathrm{~nm}$ ), but are identical to phage T4 in tail morphology. KVP40 has a feather of decoration proteins on its head $[21,22]$.

Three other T4 phages do not fit into these groups: Acinetobacter phage 133, Aeromonas hydrophila phage Aeh1 and Aeromonas salmonicida phage 65. Morphologically, phage 133 is identical to T4, whereas Aeh1 and 65 have the same heads of $133 \mathrm{~nm}$ in length as Vibrio phages KVP40 and nt-1. They were considered to be part of the "schizo-T-even" group [23] and have a T4-type tail structure [20]. CoreGenes and our supplementary phylogenetical analyses indicate that these phages are too dissimilar, by our criteria, to be included into one of the genera listed above.

The four marine cyanophages (P-SSM2, P-SSM4, S-PM2 and Syn9) infect Synechococcus or Prochlorococcus strains and harbor T4 genes causing this group to be named the "exo-T-evens" $[24,25]$. These phages have isometric heads and much longer tails than T4. CoreGenes analysis indicates that they form a group sharing $>40 \%$ proteins in common. While P-SSM2, P-SSM4 and Syn9 share 93 proteins, they show considerable dissimilarity in appearance, size, and DNA content (Table 3). Phylogenetic analysis based upon sequence alignments of gp20 (portal vertex protein [26]) and photosystem II protein D1 $[27,28]$ indicate considerable diversity exist among cultured and environmental cyanophages. This is also confirmed by an analysis of data from the marine virome from the Sorcerer II Global Ocean Sampling expedition [29]. Based upon these observations, we feel that the creation of genera within cyanophage myoviruses is premature at the present time.

Rhodothermus marinus phage RM378 (NC_004735) is a virus said to have a head of $95 \times 85 \mathrm{~nm}$ and a tail of 150 $\mathrm{nm}$ in length [30]. It was called a "ThermoT-even phage" by Filée et al. [6], but our CoreGenes analysis reveals that its proteins shows minimal sequence similarity to any T4related virus. 


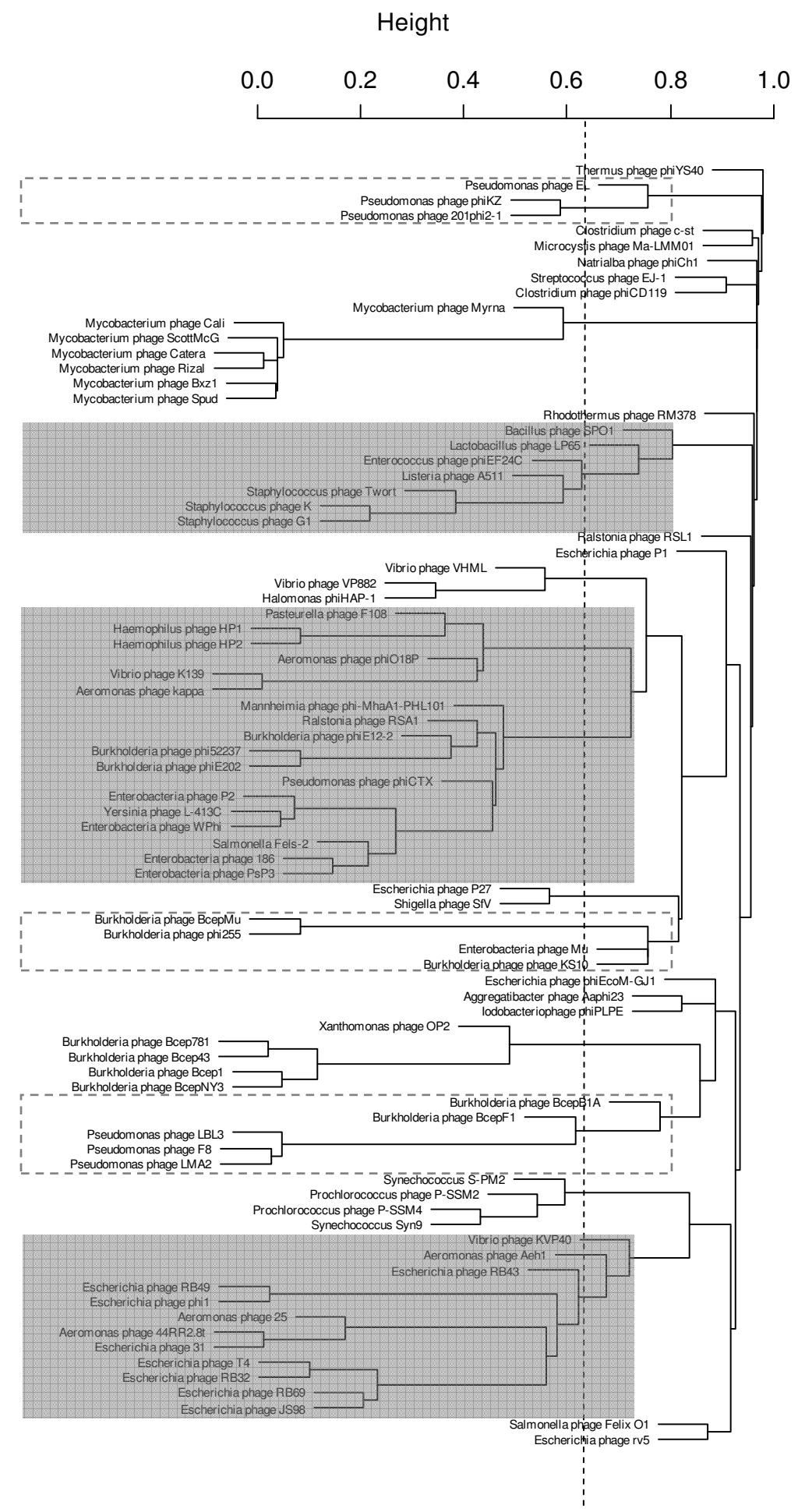

\section{Figure I}

Hierarchical cluster dendrogram of the analyzed Myoviridae. The relative dissimilarity between the phage proteomes (between 0.0 and I.0) forms the basis for the proposed groupings. The dotted lines reflects the cut-off value used for the establishment of genera, used consistently for all Myoviridae and the previously defined Podoviridae [107]. Subfamily and tentative subfamily groupings are indicated in the grey and dotted boxes, respectively. 
Table 2: Type-specific proteins in T4 phages

\begin{tabular}{|c|c|c|}
\hline Type (host) & Genome size (in kb) & Type-specific proteins \\
\hline T4 (E. coli) & $165.9-170.5$ & NP_049650, 049704, 049747, 049694 (Pin), 049626 (MotB), 049635 (ModA) \\
\hline 44RR2.8t (Aeromonas) & $161.5-173.6$ & NP_932430, 93245I, 932460, 932567, 932569, 932577 \\
\hline RB49 (E. coli) & 164.1 & NP_891619, 891621, 891622, 891626, 891736, 891753, 891760, 891800, 891816 \\
\hline RB43 (E. coli) & 178.7 & YP_239033, 239034, 239054, 239086, 239094, 239097, 239130, 2392I5, 239216, 239241 \\
\hline
\end{tabular}

\section{Peduovirinae}

This subfamily is a large phage group derived from the ICTV genus "P2-like phages" and is named the Peduovirinae. Virions have heads of $60 \mathrm{~nm}$ in diameter and tails of $135 \times 18 \mathrm{~nm}$. Phages are easily identified because contracted sheaths tend to slide off the tail core. The subfamily falls into three different groups. As shown by CoreExtractor and CoreGenes analyses, and using the $40 \%$ similarity criterion for inclusion into the same genus, phage HP1 has only 9 genes in common P2. Even if other P2 phages are considered, HP1 shares only 17 genes with any phage of the "P2-like" genus. Using the $40 \%$ similarity criterion for inclusion into the same genus, it is therefore justified to consider P2 and HP1 as members of different genera and to upgrade the present genus "P2 phages" to a subfamily.

\section{P2-like viruses nova comb}

This genus includes P2 itself and its extensively studied relative, coliphage 186. Both originate from the Pasteur Institute in Paris, France. Phage P2 is one of three phages (P1, P2, P3) isolated by G. Bertani in the beginning of the 1950's from the "Li" (Lisbonne and Carrère) strain of $E$. coli [31]. Later on, F. Jacob and E. Wollman isolated phage 186 and many other viruses from enterobacteria collected by L. Le Minor [32]. The reason for the early interest in these phages was that P2 and 186 are temperate. The analysis of the genetic control of these two modes was the starting point for ongoing fertile research on phage biology and molecular biology in general.

The genomes of phage P2 and 186 were the first P2 genomes to be fully sequenced and analyzed. Almost all $\mathrm{P} 2$ and 186 genes have been assigned a function [33-35]. Coliphages W $\Phi$ and L-413C are very similar to P2 in both gene content and gene order. They are closely related to each other, sharing all but one protein. The only genes of these phages that differ from P2 are the lysogeny-related genes, which may have been horizontally acquired and are totally different, but have been inserted at the same locations into all genomes. The only exception to this is that phage P2 has a 786 bp ORF (orf30) with unknown function inserted between the $S$ and $V$ genes. There is no such insertion in $\mathrm{W} \Phi$ and L-413C, but Pseudomonas phage ФCTX (see below) has another uncharacterized ORF located at this position. Enterobacterial phages 186, PSP3, Fels-2, and SopЕФ also share their overall gene order and many genes with $\mathrm{P} 2$, but the genes are more diverged. Unlike P2, these phages are UV-inducible due to the presence of the tum gene. In addition, they have a different lysis-lysogeny switch region. P2 phages seem to have either of two different proteins for repression of the lytic cycle. P2, W $\Phi$ and L-413C have the repressor gene $C$ whereas 186, PSP3, Fels-2, SopEФ, HP1, HP2, and K139 (below) instead have the sequence-unrelated genes $\mathrm{CI}$ and CII, both of which are equally needed for establishing lysogeny.

Mannheimia phage Ф-MhaA1-PHL101, Pseudomonas phageФСТХ, and Ralstonia phage RSA1 have many P2 genes and an overall order of structural genes that is P2like, although interspersed with some uncharacterized genes. Their presumed regulatory gene regions include additional putative and uncharacterized ORFs. Phage ФCTX has only the P2 regulatory gene ogr (transcriptional activator of the late genes) and the recombination enzyme int (integrase), Ф-MhaA1-PHL101 has repressor (CI) and antirepressor (Cro) equivalents which are most closely related to the regulatory proteins of the P22-like enterobacteria phage ST104 than to P2.

Table 3: T4 cyanophages

\begin{tabular}{cccccc}
\hline Phage & Head, $\mathbf{n m}$ & Tail length, $\mathbf{n m}$ & DNA size, kb & ORFs & References \\
\hline P-SSM2 & $110^{*}$ & $100^{*}$ & 252 & 327 & {$[103]$} \\
P-SSM4 & $70^{*}$ & $200^{*}$ & 178 & 198 & {$[103]$} \\
S-PM2 & 67 & 200 & 187 & 173 & {$[104,105]$} \\
Syn9 & 87 & 150 & 173 & 226 & {$[106]$} \\
\hline
\end{tabular}

*From published micrographs. 
Phage RSA1 seems to have only one P2-related regulatory gene, the ogr gene, although it is more related to the Ogr/ Delta-like gene in ФCTX. The RSA1 integrase is more similar to the integrases of the P2-like Burkholderia phages (ФE202, Ф52237, and ФE12-2 and P22-like viruses.

\section{HPI-like viruses}

The genome architecture of HP1 [36] and its close relative, HP2, resembles that of P2 although their cos sites, as with Pseudomonas ФCTX [37], are located next to attP rather than downstream of the portal protein-encoding gene as it is in P2. The P2 gene order is also conserved in Vibrio phages K139 [38] and $\kappa$ and the Pasteurella phage F108 [39]. As in P2, the genomes can be divided into blocks of structural and regulatory genes. The structural genes are more similar in HP1 and HP2 than the regulatory genes. The six genes coding for capsid proteins are arranged in the same order in HP1 phages and many P2 phages. The other structural genes, coding mainly for tail components, show generally no similarity to those of $\mathrm{P} 2$ phages. Only some of the regulatory genes are similar in both HP1 and P2 phages, e.g., int, CI, and repA. Regulatory genes in general are more conserved within the HP1 group.

Aeromonas phage ФO18P [40] is included into the HP1 phages. It contains slightly more genes related to HP1 than to P2, although, when looking at individual proteins, it sometimes appears to have an intermediate position. Its Rep protein is very similar to the DNA replication protein of Salmonella phage PSP3 and the A protein of phages K139, F108, WФ, and P2 homologs. The ФO18P major capsid protein is similar to the capsid proteins of phages K139, ФCTX, 186, and the Burkholderia phages.

\section{The Spounavirinae}

This proposed subfamily contains the ICTV-recognized genus "SPO1-like viruses" and, on the basis of our results, a proposed new genus (the "Twort-like viruses") and two peripherally related viruses, Lactobacillus plantarum phage LP65 [41] and Enterococcus faecalis phage $\phi$ EF24C $[42,43]$. All of these are virulent, broad-host range phages which infect members of the Firmicutes. They possess isometric heads of 87-94 nm in diameter and conspicuous capsomers, striated 140-219 nm long tails, a double base plate, and globular structures at the tail tip. The latter have been resolved as base plate spikes and short kinked tail fibers with six-fold symmetry [44]. Members of this group usually possess large (127-142 kb) nonpermuted genomes with $3.1-20 \mathrm{~kb}$ terminal redundancies $[45,46]$. The proposed name for this subfamily is derived from SPO plus una (latin for "one").

While the head diameter of Bacillus phage SPO1, of $87 \mathrm{~nm}$ [47], is consistent with membership in the group, its tail is significantly shorter than that of most members (140-
$150 \mathrm{~nm})[3,48]$, and, the DNA contains 5-hydroxymethyluracil (HMU) rather than thymine. The outliers of this group comprise phages LP65 [41] and $\phi E F 24 C[42,43]$. At $193 \mathrm{~nm}$, the tail of phage LP65 is similar in length to that of other members of this group, but its genome is not terminally redundant [41]. Lastly, the genome size (142 kb), proteome and morphology of Enterococcus phage $\phi \mathrm{EF} 24 \mathrm{C}$ is clearly consistent with membership in this group (head diameter $93 \mathrm{~nm}$; tail length $204 \mathrm{~nm}$ ), but its genome is circularly permuted. Their close relationship was discussed in a recent paper [44].

Using a BLASTP raw threshold score of 100 and CoreGenes 3.0 http://binf.gmu.edu:8080/CoreGenes3.0/ to compare the proteomes of Twort, A511, LP65, and $\phi E F 24 \mathrm{C}$ against SPO1, we identified two clusters of genes which are conserved. These corresponded to packaging and morphogenesis genes (SPO1 gp2.11 to gp16.2); and the cluster of replication genes, including helicase, exonuclease, primase, and resolvase (SPO1 gp19.5 - gp24.1). The DNA polymerases (SPO1 gp31 and homologs) of these phages are related more closely to bacterial-type I DNA polymerases than other phage deoxynucleotide polymerizing enzymes. The presence of host-related proteins in viruses has been observed by Dinsdale et al. [49] and elegantly explained by Serwer [50]. Metagenomic studies by the former group indicate the presence of numerous host-related proteins, including those related to motility and chemotaxis, in the virome fractions. While the functional significance of photosynthetic protein $p s b A$ in cyanophage genomes has been conclusively shown $[51,52]$, the presence of host-related sequences should still be considered with healthy skepticism if the only data is the presence of homologs.

\section{SPOI-like viruses}

The current ICTV genus "SPO1 viruses" comprises some 10 Bacillus phages and Lactobacillus phage 222a; only the genome of SPO1 has been sequenced [53]. All SPO1-like Bacillus phage genomes that have been studied contain 5hydroxymethyluracil (HMU) instead of thymine and encode dUMP hydroxymethylase activity (SPO1 gp29). This phage also contains the unique 171-amino acid head decoration protein gp29.2. Whether this is unique to members of this genus will require the sequencing of additional genomes. Using cryo-electron microscopy, Duda and coworkers [54] confirmed the earlier observation [47] that the icosahedral head of SPO1 head has the triangulation number $\mathrm{T}=16$ rather than the more common $\mathrm{T}=25$. This feature is also shared with eukaryotic herpesviruses.

\section{Twort-like viruses}

The phages form a fairly homogeneous group of virulent phages infecting staphylococci (Twort, G1, K) [55] and 
Listeria (A511, P100) [56]. The group is named after phage "Twort," which may be a descendant of the original bacteriophage described by F.W. Twort in 1915 [57]. Apparently, this phage was deposited at the Pasteur Institute of Paris in 1947 when Twort was invited there to retell the story of his discovery (personal communication to H.W.A. by J.-F. Vieu, curator of the phage collection of the Pasteur Institute; 1983).

\section{B. Additional ICTV-recognized genera}

\section{Mu-like viruses}

Phage $\mathrm{Mu}$ is morphologically almost identical to phage P2. Although phage Mu shares features (e.g. replicative transposition) with BcepMu [58] and two siphoviruses, Pseudomonas phages B3 and D3112 [59,60], this phage holds a unique position within the Myoviridae, since its proteome displays only limited homology to any other completely sequenced phage genome.

Mu and P2 have only 4 proteins in common (overall 9.8\% similarity). P2 differs from Mu by genome size $(33.6 \mathrm{~kb}$ vs. $36.7 \mathrm{kp}$ in $\mathrm{Mu}$ ), the number of proteins (43 proteins vs. 55 in $\mathrm{Mu}$ ), gene order, and the presence of a single capsid protein and cohesive ends in its DNA. By contrast, $\mathrm{Mu}$ has two capsid proteins and two sets of tail fiber genes and replicates via transposition, which is a very rare mode of replication. $\mathrm{Mu}$ shares this characteristic with BcepMu, but BcepMu has no tail fiber inversion system and only a limited proteomic correlation to $\mathrm{Mu}$ (9 gene homologs; $16.4 \%$ similarity).

Only coliphage D108, as shown by heteroduplex analysis, shows significant similarity to Mu to warrant inclusion in the $\mathrm{Mu}$ genus [61]. Unfortunately, only portions of the genome of D108 have been sequenced. Putative Mu proviruses have been reported in a wide range of bacteria [6264]. CoreGenes analysis revealed that only some of them can be reasonably described as Mu proviruses, namely, Escherichia blattae prophage MuEb [65], Haemophilus influenzae Rd prophage Hin-Mu [66], and Shewanella oneidensis prophage MuSo2 [NC_004347].

\section{PI-like viruses}

This small genus comprises coliphage P1, famous for its cre recombinase and the large-insert cloning vectors engineered on the basis of the phage genome [67], P7 (AF503408) and its not yet sequenced putative relative D7. Phage P1 stands out from any of the phages described here by its morphology. Phage P1 differs from the phages described here by size and morphology. It has a very large head of approximately $85 \mathrm{~nm}$ in diameter and a very long tail of $228 \times 18 \mathrm{~nm}$ in the extended state. Tails have base plates and $90 \mathrm{~nm}$ long, kinked fibers. The tails of related, not yet sequenced phages of enterobacteria and Aeromonas vary between 170 and $240 \mathrm{~nm}$ in length. All phages of this group produce three types of head-size variants (small, normal, intermediate).

\section{Additional genera within the Myoviridae}

\section{Bcep78I-like viruses}

"Bcep" stands for $\underline{B}$ urkholderia cepacia, and phages with this designation infect bacteria belonging to the B. cepacia genomic complex. The Bcep781 phages form a group of virulent myophages of which the genome sequence of five members, Bcep781, Bcep1, Bcep43, BcepNY3 and Xanthomonas phage OP2, is known $[68,69]$. The Bcep781 phages are small viruses with distinctly shorter tails than P2, Mu, and BcepMu [68].

The genomes of these phages range from 46 to $49 \mathrm{~kb}$ in size and encode 66 to 71 proteins. The four Bcep phages encode a single tRNA each. They form a homogeneous phage group not just in terms of sequence, but also by their distinctive genome organization compared to other groups. The genomes of the Bcep781 phages are divided into four gene clusters encoded on alternate strands such that, using Bcep781 as the example, genes 1 through 19 and 29 through 51 are present on the bottom strand while genes 20 through 28 and 52 through 66 are present on the top strand. Head genes are located in the first cluster and tail genes are located in the third cluster. The virion major capsid and decoration proteins, Bcep781 gp12 and gp13, were identified by protein sequencing and show some similarity to head proteins from the "PB1-like viruses" group. Several tail morphogenesis proteins, corresponding to Bcep781 gp29 through gp52, can be linked to P2 tail genes by PSI-BLAST. In contrast to structural genes, genes for DNA replication and lysis are scattered throughout the genome. The lysis genes of these phages are not organized into a cassette but instead overlapping $\mathrm{Rz}$ and Rz1 genes are separated from the endolysin and holin genes [70]. A distinctive feature of these phages is the presence of highly, maybe completely, circularly permuted genomes. The terminases of these phages are strongly related to other pac-type phages that also have highly permuted genomes [71].

\section{BcepMu-like viruses}

This group was named "BcepMu-like viruses" because, like $\mathrm{Mu}$ and unlike most other phages, its members utilize transposition for replication. The distinctive genomic feature implicating the use of replicative transposition is the presence of random host DNA sequences at either end of the packaged virion DNA [58]. These host sequences are derived from excision of prophage DNA from random sites scattered over the host genome. This requires fundamental differences in terminase function as compared to more typical terminases that utilize concatemers of phage genomic DNA as a substrate. This is reflected by the homology between BcepMu TerL and Mu TerL. Another 
genome feature shared by BcepMu and $\mathrm{Mu}$ is the presence of genomic terminal CA dinucleotide repeats, a feature common in many transposons. Furthermore, BcepMu and $\mathrm{Mu}$ seem to be morphologically identical.

Despite these similarities, BcepMu and its close relative $\phi \mathrm{E} 255$ have marked differences in genome organization and minimal overall protein sequence similarity to $\mathrm{Mu}$, explaining why they have not been grouped together. The putative BcepMu transposase is not related to the $\mathrm{Mu}$ transposase, TnpA, but instead is a distant member of the Tn552-IS1604 transposase family. The BcepMu genome is organized into two clusters, with genes 1 through 13 encoded on the bottom strand and genes 17 through 52 on the top strand. The cluster of bottom strand genes includes transcription regulators, the transposase, and a number of small genes of unknown function. The lysogeny control region is likely to include genes 16 and 17 , located at the interface of the bottom strand/top strand gene clusters. This is followed by a lysis cassette consisting genes encoding a holin, endolysin, Rz and Rz1. Proteins 27 through 51 encompass the head and tail morphogenesis cassette. The BcepMu tail biosynthetic cassette proteins are recognizably related both in sequence and in gene order to those of coliphage P2.

BcepMu is present as a prophage in many B. cenocepacia strains of the human pathogenic ET2 lineage $[58,72]$. Phage $\phi \mathrm{E} 255$ is a phage of the soil saprophyte $B$. thailandensis [NC_009237]. BcepMu phages, however, are not limited to Burkholderia hosts as related prophage elements have been identified in the genomic sequence of many other bacteria, for example Chromobacterium violaceum [NP_901809].

\section{Felix OI-like viruses}

Salmonella phage Felix $\mathrm{O} 1$ has a relatively large head (70 $\mathrm{nm}$ in diameter) and a tail of $138 \times 18 \mathrm{~nm}$ characterized by subunits overlapping each other like roof tiles and showing a criss-cross pattern like phages PB-1 and F8. Notably, it exhibits small collars and eight straight tail fibers. Upon contraction, the base plate separates from the sheath. The type virus Felix $\mathrm{O} 1$ is widely known as a diagnostic Salmonella-specific phage [21]. Until recently, the genomic sequence $(86.1 \mathrm{~kb})$ of phage Felix $\mathrm{O} 1$ was unique and was considered, as such, a "genomic orphan", but two related genomes have been recently characterized, though their sequences have yet to be deposited to the public databases. They are coliphage wV8 and Erwinia amylovora phage $\phi E a 21-4$ (DNA sizes 88.5 and $84.6 \mathrm{~kb}$, respectively $[73,74]$.

\section{HAPI-like viruses}

This genus contains two marine phages, Vibrio parahaemolyticus phage VP882 (NC_009016) and Halomonas aqua- marina phage $\phi$ HAP-1 [75]. Both are temperate viruses possessing 38-43 kb genomes which lack integrase genes. While our proteomic analysis and the literature suggests that Vibrio harveyi phage VHML [76,77] should be included in this genus, there is no evidence that this phage can be propagated: it is only produced after induction, does not plaque, and must be considered a defective prophage. The data presented by Mobberley et al. [78] show that $\phi$ HAP-1 exists as a linear prophage in lysogens and possesses a protelomerase (ORF34, YP_001686770.1) and a partitioning protein (ParA homolog, ORF33, YP_001686769.1) which are homologous to proteins encoded by VHML and VP882. While these viruses share some homology with the coliphage P2, this is largely restricted to the genes associated with tail morphogenesis $\mathrm{V}(\mathrm{gp} V, W, J, I, H, G)$ and F operons (gpFI, FII, E, T, U, D). Based upon their radically different life cycle from the other P2 phages, we have chosen not to include them in the Peduovirinae.

\section{BzxI-like or I3-like viruses}

Myoviruses are exquisitely rare in the Actinobacteria (only an estimated $1 \%$ of all attempts to isolate phages from cultures was successful [79]). Phages I3, Bzx1 and Catera are characterized by heads of $80 \mathrm{~nm}$ in diameter and unusually short tails of $80 \mathrm{~nm}$ in length with a cup-shaped base plate. They do not resemble any other mycobacteriophages nor any other myovirus. We propose that this genus contains the following eight Mycobacterium smegmatis bacteriophages: I3, Bxz1, Cali, Catera, Myrna, Rizal, ScottMcG and Spud. Phage I3, which has been the first to be described, is the type virus of the newly proposed myovirus genus although it has not yet been fully sequenced. Within this assemblage, we identified a distinct subtype which show $>90 \%$ protein similarity to Bxz1 (Cali, Catera, Rizal, ScottMcG and Spud) and genomes of 154-156 kb [80,81]. Mycobacteriophage Myrna, with a genome of 164 $\mathrm{kb}$, shares approximately $45 \%$ of proteins with the Bxz1 subgroup phages. Interesting features include the presence of adenylosuccinate synthase homologs among the Bxz1 subgroup (gp250) and its absence in the genome of Myrna. The latter possesses several proteins not present in the Bxz1 group, including the large hypothetical proteins gp187 (YP_002225066.1) and gp243 (YP_002225120.1), a putative nicotinate phosphoribosyltransferase (gp263, YP_002225140.1) and ATP-dependent protease (gp262, YP_002225139.1).

\section{6. phiCD / /9-like viruses}

These are all integrative temperate phages of Clostridium difficile with genomes ranging from $51-60 \mathrm{~kb}$ in size and a $\mathrm{mol} \% \mathrm{G}+\mathrm{C}$ of 28.7-29.4 [82-84]. The genus is named after its first fully sequenced member. In each case, the electron micrographs are of poor quality $[84,85]$ or the measurements are very variable with large standard deviations 
[85]. Virus head diameters are given as $50-65 \mathrm{~nm}$ and tail lengths are said to range from 110 to $210 \mathrm{~nm}$ [82-84]. In certain cases, their annotation is also questionable, The multiple repressor/antirepressors annotated in the genomes of $\Phi \mathrm{CD} 27$ and $\phi \mathrm{C} 2$ do not appear to contain helix-turn-helix or other DNA binding motifs [86]; nor the presence, in the latter phage, of ParA/ParB homologs. What unites these viruses, in addition to similar proteomes, is the presence in each of a cytosine-C5 specific DNA methylase (pfam00145, DNA_methylase, C-5 cytosine-specific DNA methylase; ФCD119 protein YP_529611.1) and a DNA replication cassette composed of three proteins: a DnaD (primosome recruiting protein, presumably analogous to lambda gpO and P22 gp18; ФCD119 protein YP_529603.1), a hypothetical protein (misidentified in $\Phi C D 27$ as a putative resolvase/integrase and missed entirely in the annotation of (CD119) and a single-stranded DNA binding protein.

\section{7. phiKZ-like viruses}

Phages $\phi K Z$ and EL are members of a group of giant phages isolated, to date, only in Pseudomonas species. Their heads are isometric, $120 \mathrm{~nm}$ in diameter, and they possess $190 \mathrm{~nm}$-long tails. The phage heads contain an inner body. The DNA of $\phi \mathrm{KZ}$ is over $280 \mathrm{~kb}$ in size and has 306 ORFs, most of which are unrelated to ORFS of any known protein [87], while EL contains 201 ORFs within its $211 \mathrm{~kb}$ genome [88]. These two phages and Pseudomonas phage Lin 68 have recently been proposed as part of a genus "phiKZ viruses" [89]. We now consider that the differences (number of ORFs, $\mathrm{mol} \% \mathrm{G}+\mathrm{C}$, protein homologs) between $\phi \mathrm{KZ}$ and EL exclude EL from membership in the same genus. Indeed, the recent analysis of novel Pseudomonas phage 201ф2-1 [90] showed this phage to have a strong correlation to $\phi K Z$ (167 similar proteins), suggesting that it is a true member of the phiKZ virus genus.

\section{8. $P B /$-like viruses}

This genus is named after the first isolated member of this group (PB1) [91]. Morphological and DNA-DNA hybridization studies by $\mathrm{V}$. Krylov indicated that the following Pseudomonas phages were related: E79, 16, 109, 352, 1214, FS, 71, 337, $\phi C 17$, SL2, B17 [92]. The sequences of a number of viruses belonging to this genus, namely F8, BcepF1, PB1, 14-1, LBL3, LMA2, and SN (P.-J. Ceyssens, personal communication) have now been completed. None of these phages encodes a recognizable integrase, suggesting that they are virulent.

Phage F8 is one of the Pseudomonas typing phages from the Lindberg set which includes six more similar phages $[93,94]$. It possesses a $70-\mathrm{nm}$ wide head with visible capsomers and a $138 \mathrm{~nm}$-long tail, four short straight tail fibers and a base plate that separates from the sheath upon contraction. The tail exhibits no transverse striations, but presents a criss-cross pattern [95]. This criss-cross pattern is a rare feature that has only been observed in phage Felix $\mathrm{O} 1$.

BcepF1 was isolated from soil by enrichment culture [96] using a Burkholderia ambifaria strain as its host (E.J. Summer and C.F. Gonzalez, unpublished). The BcepF1 genome is $72 \mathrm{~kb}$ in size and encodes 127 proteins while the genome of $\mathrm{F} 8$ is $66 \mathrm{~kb}$ and encodes 91 proteins [97]. Both genomes are organized into four alternating, unequal gene clusters on the top and bottom strands. The phages share 43 recognizable homologous proteins. The shared proteins specify virion morphogenesis, DNA metabolism and packaging and include a number of hypothetical proteins of unknown function.

A striking feature of both F8 and BcepF1 is the large number of small genes, all encoding hypothetical proteins and clustered together. In BcepF1, the first $20 \mathrm{~kb}$ of the genome, encoding 62 proteins, is devoted almost exclusively to these. In F8, there are two clusters of $8 \mathrm{~kb}$ (encoding gp1 through gp16, except gp4, TerL) and $4 \mathrm{~kb}$ (encoding proteins gp 77 through gp91) of primarily small hypothetical novel genes. These heterogeneous regions are largely responsible for the difference in genome size and protein content between the two phages. It has generally been assumed that these small proteins are involved in host take-over (E. Kutter, personal communications) which appears to be substantiated by the results of Liu and coworkers [98].

Phages F8 and BcepF1 have some similarity to myophage BcepB1A, which is itself related in a mosaic fashion to the Bcep781 group of phages [68]; however, these similarities are essentially limited to morphogenetic proteins. As in the Bcep781 phages, several putative tail assembly proteins of F8 and BcepF1 can be linked to those of P2 by PSIBLAST.

\section{Single phages}

In addition to the phage groups listed above, complete genome sequences are available for phages without apparent relatives, namely Aggregatibacter (formerly Actinobacillus) phage Aa $\phi 23$; Bacillus thuringiensis phage 0305\$8-36, Clostridium phages c-st, Escherichia phages $\phi \mathrm{EcoM}-\mathrm{GJ} 1$ and rV5; Microcystis phage Ma-LMM01, Ralstonia phage RSL1, Rhodothermus phage RM378; Streptococcus phage EJ-1, and Thermus phage $\phi \mathrm{YS} 40$. References to these phages may be found in the NCBI RefSeq database.

\section{General summary}

The comparison of proteomes by CoreGenes/CoreExtractor BLASTP programs appears to be a decisive progress in classifying tailed bacteriophages, i.e., our results corrobo- 
Table 4: Concordance of classifications

\begin{tabular}{|c|c|c|c|c|c|}
\hline Classification & ICTV & Proteomic Tree 2 & $\begin{array}{ll}--- \\
--\end{array}$ & Phage_Finder & This work \\
\hline Reference & $\begin{array}{l}\text { ICTV VIIIth } \\
\text { Report, } 2005\end{array}$ & $\begin{array}{l}\text { Edwards and } \\
\text { Rohwer, } 2005\end{array}$ & Serwer et al., 2004 & Fouts, 2006 & \\
\hline Approach & Traditional & Signature genes & Large terminase & & CoreGenes \\
\hline \multirow[t]{5}{*}{ Phage or phage group } & $\begin{array}{l}\text { T4, AehI, KVP40, } \\
\text { RB43, RB49, 25, 3I } \\
\text { 44RR2.8t, } 65\end{array}$ & $\mathrm{~T} 4$ & T4, KVP40, RB49 & & $\begin{array}{l}\text { T4, AehI, KVP40, } \\
\text { RB43, RB49, 25, 3। } \\
\text { 44RR2.8t, } 65\end{array}$ \\
\hline & PI & & & $\mathrm{PI}$ & $\mathrm{PI}$ \\
\hline & $\begin{array}{l}\text { P2, Fels-2, HPI, HP2, } \\
\mathrm{K} 139, \phi C T X, 186\end{array}$ & P2. HPI, HP2, $\phi C T X$ & $\begin{array}{l}\text { P2, Fels-2, HPI, HP2, } \\
\text { L4I3-C, I86; Mu }\end{array}$ & $\begin{array}{l}\mathrm{P} 2, \phi C T X, 186 \text { (HPI } \\
\text { occupies a separate } \\
\text { position) }\end{array}$ & $\begin{array}{l}\text { P2, Fels-2, HPI, HP2, } \\
\text { KI39, L-4I3C, } \phi C T X \text {, } \\
\text { I } 86\end{array}$ \\
\hline & Mu & $\mathrm{Mu}$ & & & $\mathrm{Mu}$ \\
\hline & $\begin{array}{l}\text { SPOI } \\
\Phi H\end{array}$ & $\mathrm{~K}$ & & PI00, Twort & SPOI, K, PI00, Twort \\
\hline
\end{tabular}

Comparison of our results with those of the ICTV (ICTV VIIIth Report, 2005), Proteomic Tree 2 (Edwards and Rohwer, 2005), Phage_Finder

(Fouts, 2006) and phylogeny of terminases (Serwer et al., 2004).

rate the existing ICTV classification of the Myoviridae and are generally well compatible with other informaticsbased studies (Table 4), like the reticulate clustering based on gene families [99] (Lima-Mendez, personal communication). Our studies also refine certain relationships and suggest new ones. Specifically, we propose three new subfamilies (Peduovirinae, Teequatrovirinae, Spounavirinae) and eight new genera (Bcep781, BcepMu, Bzx1, Felix, HAP1, PB1, phiCD119 and phiKZ-like viruses). The individualization of genera containing two or three members as well as of genomic orphans, e.g. coliphage P1 without apparent homologs, is taxonomically as valuable and important as the confirmation of the large T4 and P2 groups and in total agreement with previous informaticsbased classifications (Table 4). Our studies once again prove the utility of the dual CoreGenes/CoreExtractor approach to defining relationships between large numbers of virus genomes. These relationships carry evolutionary relevance, since our proteomic analyses, combined with the phylogenetic studies [100], suggest that the Myoviridae are mainly influenced by vertical evolution rather than by horizontal gene transfer. As observed in the Cluster dendrogram, the clusters are populated unevenly - several include only one phage while two, the largest, include dozens phages. This reflects the fact that past phage research has focused on coliphages, and suggests that we should broaden our research to include phages from a broader range of bacteria.

Among the 102 analyzed Myoviridae, phage Mu displayed the most significant evidence of horizontal gene exchange. This virus is related to three members of pilusspecific Siphoviridae infecting Pseudomonas aeruginosa (DMS3, D3112, B3 [59,60,101]), sharing 20 to $40 \%$ of its genes with each of them. These phages can be viewed as true hybrids, produced by recombination of different ancestors and, like the couple lambda/P22 (to be described in a future paper), cross family boundaries based on tail morphology. Nonetheless, the majority of Myoviridae, when forced to cluster, do so in a logical manner: upgrading of the ICTV genus "P2 phages" to the Pduovirinae with two genera ("P2 viruses" and "HP1 viruses") is a straightforward proposal and the same is true for the Spounavirinae (SPO1 viruses and Twort viruses).

Relationships among T4-like phages are more complicated. We reject the postulated inclusion of the cyanophages since their overall similarity to $\mathrm{T} 4$ is too low for consideration, at least according to our criteria. Comeau and Krisch [29] have recently recognized three groups of T4-related phages. The "Near T4" group containing the Tevens, Pseudo T-evens, and Schizo T-evens; the "Far T4" clade including Exo-T4 phage RM378; and, the "Cyano T4" assemblage. We believe that the latter are sufficiently different from the other $\mathrm{T} 4$ viruses to be excluded from the Teequatrovirinae at this time. This implies that this subfamily currently contains two distinct genera: T4 and KVP40 viruses. Within our restricted "T4 phages" genus, four subtypes were identified (T4-type, 44RR2.8t-type, RB43-type and the RB49-type viruses). This is confirmed by the phylogenetic studies of Filée et al. [5] and our unpublished results. Since these subtypes include different species, no equivalent taxonomic level is currently available in the official ICTV classification. Perhaps the introduction of a "subgenus" level should be considered in order to account for the complexity of T4-related phages. Alternately, a general elevation of all taxonomic levels (from the subfamily level) may be envisioned. 
This study illustrates the great diversity and biological richness of tailed phages. The number of independent genera is not surprising in view of the antiquity of tailed bacteriophages, which are found in archaea and bacteria and may predate the separation of these domains. It can be expected that many more phage groups will be found or individualized in the future. For example, this study does not include giant Bacillus phage $\mathrm{G}$, the largest bacterial virus with a genome of 497,513 bp and 684 genes [102] whose sequence is not yet available for comparison.

We reiterate our statement in our publication on the taxonomy of the Podoviridae, "We highly recommend that the entire genome of any newly sequenced phage be thoroughly screened (BLASTX) against the Entrez Query "Viruses [ORGN]" databases to reveal all similarities for quick identification of potential relationships. A validation step using CoreGenes is essential and more precise for individual comparisons [2]."

\section{Conclusion}

Myoviridae can be classified by their proteomes into subfamilies and genera. This classification is in close agreement with ICTV - and other informatics-based classifications.

\section{Methods}

\section{Phages and bioinformatic tools}

This study is limited to the genomes of completely sequenced, viable Myoviridae from the databases of NCBI http://www.ncbi.nlm.nih.gov/ and the Tulane University at New Orleans, LA (GT4P, "Genomes of the T4 Phages"; http://phage.bioc.tulane.edu/, excluding prophages without a virion stage. We follow here the ICTV which classifies viable viruses only. Prophages and proviruses, prophage fragments, defective viruses, phage-like "bacteriocins", virus-like or phage-likes particles from sections or the environment, viroids, satellite viruses, plasmids, or transposons, or artificial virus hybrids are not considered. CoreExtractor and CoreGenes software were used as described previously [2]. In the case of CoreExtractor, the BLASTX analysis of phage gene products was performed using the NCBI Batch BLAST server, http://green gene.uml.edu/programs/NCBI_Blast.html hosted by the University of Massachusetts at Lowell, MA. Searches were performed against the NCBI nonredundant database (BLOSUM45 matrix, with a 0.05 expectancy cut-off value) (Additional Figure 2). Several versions of CoreGenes are available, with each upgrade incorporating previous functions, at http://www.binf.gmu.edu/genometools.html. In particular, for the current study, a version, CoreGenes3.0beta, was developed specifically for tallying the total number of genes contained in the genomes. It also displays a percent value of genes in common with a specific genome. Additionally, this version finds unique genes between two genomes. The BLASTP stringency setting was set at its default value (75). Proteins containing at least 132 amino acid residues were subjected to BLASTP analysis at NCBI or Tulane University.

\section{Hierarchical cluster dendrogram}

Cluster analysis was used to visualize the structure of the proteomic data. We constructed a dissimilarity matrix from the CoreExtractor matrix. The dissimilarity between two phage genomes was taken as one (1) minus the average of the two reciprocal correlation scores in the CoreExtractor matrix (Figure S1B). Subsequently, single linkage hierarchical clustering was performed using "The R Project for Statistical Computing" software http://www.rproject.org/.

\section{Competing interests}

The authors declare that they have no competing interests.

\section{Authors' contributions}

All the authors contributed to the writing of this manuscript. RL and AMK planned and executed the comparisons. RL, PM and DS developed the software used. Cluster dendrograms were generated by PD.

\section{Additional material}

\section{Additional file 1}

CoreExtractor comparison of Myoviridae phages. A. This Excel figure shows relative correlation scores (above 10\%), based on the number of homologous proteins between two phages. Colour tags are added to visualize these correlations (from green to red for increasing correlation scores). B. Corresponding dissimilarity matrix.

Click here for file

[http://www.biomedcentral.com/content/supplementary/14712180-9-224-S1.XLSX]

\section{Acknowledgements}

The authors thank Michael Graves (Greengene, University of Massachusetts at Lowell, MA) for access to the NCBI Batch BLAST server and Erika Lingohr (Laboratory for Foodborne Zoonoses) for her computer assistance. We also thank lan Molineux, Elizabeth Kutter, Arianne Toussaint, Gipsi Lima-Mendez, Arcady Mushegian, Martin Loessner, Viktor Krylov, Harald Brüssow, David Prangishvili and Jim Karam for helpful discussions. A.K. is supported by a Discovery Grant from the Natural Sciences and Engineering Research Council of Canada. RL, H-WA and AK are members of the ICTV Subcommittee for Viruses of Prokaryotes. DS wishes to congratulate his graduate advisor Professor Maurice J. Bessman of The Johns Hopkins University on the occasion of his emeritus status after 50 contiguous years of funded research and upon his 80th birthday July 2008.

\section{References}

I. Zafar N, Mazumder R, Seto D: CoreGenes: a computational tool for identifying and cataloging "core" genes in a set of small genomes. BMC Bioinformatics 2002, 3:12. 
2. Lavigne R, Seto D, Mahadevan P, Ackermann H-W, Kropinski AM: Unifying classical and molecular taxonomic classification: analysis of the Podoviridae using BLASTP-based tools. Research in Microbiology 2008, 159:406-4I4.

3. Fauquet CM, Mayo MA, Maniloff J, Desselberger U, Ball A: Virus Taxonomy. In VIIlth Report of the International Committee on Taxonomy of Viruses Edited by: Fauquet CM, Mayo MA, Maniloff J, Desselberger U, Ball A. New York, NY: Elsevier Academic Press; 2005:35-85.

4. Jia Z, Ishihara R, Nakajima Y, Asakawa S, Kimura M: Molecular characterization of T4-type bacteriophages in a rice field. Environmental Microbiology 2007, 9:1091-1096.

5. Filée J, Bapteste E, Susko E, Krisch HM: A selective barrier to horizontal gene transfer in the T4-type bacteriophages that has preserved a core genome with the viral replication and structural genes. Molecular Biology \& Evolution 2006, 23: 1 688- 1696.

6. Filée J, Tétart F, Suttle CA, Krisch HM: Marine T4-type bacteriophages, a ubiquitous component of the dark matter of the biosphere. Proceedings of the National Academy of Sciences of the United States of America 2005, 1 02: I 247 I-I 2476.

7. Klausa V, Piesiniene L, Staniulis J, Nivinskas R: Abundance of T4type bacteriophages in municipal wastewater and sewage. Ekologija (Vilnius) 2003, I:47-50.

8. Zuber S, Ngom-Bru C, Barretto C, Bruttin A, Brüssow H, Denou E: Genome analysis of phage JS98 defines a fourth major subgroup of T4-like phages in Escherichia coli. Journal of Bacteriology 2007, | 89:8206-82|4

9. Comeau AM, Bertrand C, Letarov A, Tétart F, Krisch HM: Modular architecture of the T4 phage superfamily: a conserved core genome and a plastic periphery. Virology 2007, 362:384-396.

10. Nolan JM, Petrov V, Bertrand C, Krisch HM, Karam JD: Genetic diversity among five T4-like bacteriophages. Virology Journal 2006, 3:30.

II. Petrov VM, Nolan JM, Bertrand C, Levy D, Desplats C, Krisch HM, Karam JD: Plasticity of the gene functions for DNA replication in the T4-like phages. Journal of Molecular Biology 2006, 36 1:46-68.

12. Desplats C, Dez C, Tétart F, Eleaume H, Krisch HM: Snapshot of the genome of the pseudo-T-even bacteriophage RB49. Journal of Bacteriology 2002, 184:2789-2804.

13. Monod C, Repoila F, Kutateladze M, Tétart F, Krisch HM: The genome of the pseudo T-even bacteriophages, a diverse group that resembles T4. Journal of Molecular Biology 1997, 267:237-249.

14. Miller ES, Heidelberg JF, Eisen JA, Nelson WC, Durkin AS, Ciecko A, Feldblyum TV, White O, Paulsen IT, Nierman WC, Lee J, Szczypinsk $B$, Fraser CM: Complete genome sequence of the broad-hostrange vibriophage KVP40: comparative genomics of a T4related bacteriophage. Journal of Bacteriology 2003, 185:5220-5233.

15. Noguchi T, Takahashi H: A novel expression system for production of a labile protein in Escherichia coli by infection with cytosin-substituting T4 phage. Agricultural and Biological Chemistry I991, 55:2507-25I3.

16. Skorupski K, Tomaschewski J, Rüger W, Simon LD: A bacteriophage T4 gene which functions to inhibit Escherichia coli Lon protease. Journal of Bacteriology 1988, 170:3016-3024.

17. Tiemann B, Depping R, Gineikiene E, Kaliniene L, Nivinskas R, Ruger W: ModA and ModB, two ADP-ribosyltransferases encoded by bacteriophage T4: catalytic properties and mutation analysis. Journal of Bacteriology 2004, 186:7262-7272.

18. Pulitzer JF, Colombo M, Ciaramella M: New control elements of bacteriophage T4 pre-replicative transcription. Journal of Molecular Biology 1985, 182:249-263.

19. Kim JS, Davidson N: Electron microscope heteroduplex study of sequence relations of $\mathrm{T} 2, \mathrm{~T} 4$, and $\mathrm{T} 6$ bacteriophage DNAs. Virology 1974, 57:93-III

20. Ackermann $\mathrm{H}-\mathrm{W}$, Krisch HM: A catalogue of T4-type bacteriophages. Archives of Virology 1997, 142:2329-2345.

21. Ackermann H-W, DuBow MS: Viruses of Prokaryotes Boca Raton, FL: CRC Press; 1987

22. Ackermann H-W, Kasatiya SS, Kawata T, Koga T, Lee JV, Mbiguino A, Newman FS, Vieu JF, Zachary A: Classification of Vibrio bacteriophages. Intervirology 1984, 22:6I-7I.

23. Tétart F, Desplats C, Kutateladze M, Monod C, Ackermann H-W, Krisch HM: Phylogeny of the major head and tail genes of the wide-ranging T4-type bacteriophages. Journal of Bacteriology 200I, I 83:358-366.

24. Desplats C, Krisch HM: The diversity and evolution of the T4type bacteriophages. Research in Microbiology 2003, I 54:259-267.

25. Hambly E, Tétart F, Desplats C, Wilson WH, Krisch HM, Mann NH: A conserved genetic module that encodes the major virion components in both the coliphage T4 and the marine cyanophage S-PM2. Proceedings of the National Academy of Sciences of the

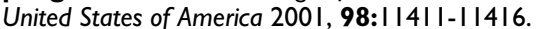

26. Short CM, Suttle CA, Short CM, Suttle CA: Nearly identical bacteriophage structural gene sequences are widely distributed in both marine and freshwater environments. Applied \& Environmental Microbiology 2005, 7 I:480-486.

27. Sharon I, Tzahor S, Williamson S, Shmoish M, Man-Aharonovich D, Rusch DB, Yooseph S, Zeidner G, Golden SS, Mackey SR, Adir N, Weingart U, Horn D, Venter JC, Mandel-Gutfreund Y, Beja O: Viral photosynthetic reaction center genes and transcripts in the marine environment. ISME Journal 2007, I:492-50 I.

28. Tzahor S, Man-Aharonovich D, Kirkup BC, Yogev T, Berman-Frank I, Polz MF, Beja O, Mandel-Gutfreund Y: A supervised learning approach for taxonomic classification of core-photosystemII genes and transcripts in the marine environment. $B M C$ Genomics 2009, 10:229.

29. Comeau AM, Krisch HM: The capsid of the T4 phage superfamily: The evolution, diversity, and structure of some of the most prevalent proteins in the biosphere. Molecular Biology \& Evolution 2008, 25:1321-1332.

30. Blondal T, Hjorleifsdottir SH, Fridjonsson OF, Aevarsson A, Skirnisdottir S, Hermannsdottir AG, Hreggvidsson GO, Smith AV, Kristjansson JK: Discovery and characterization of a thermostable bacteriophage RNA ligase homologous to T4 RNA ligase I. Nucleic Acids Research 2003, 3 I:7247-7254.

31. Bertani G: Studies on lysogenesis. I. The mode of phage liberation by lysogenic Escherichia coli. Journal of Bacteriology I95I, 62:293-300.

32. Jacob F, Wollman EL: Sur les processus de conjugaison et de recombinaison chez Escherichia coli. I. - L'induction par conjugaison ou induction zygotique. Annales de l'Institut Pasteur 1956, $91: 486-510$

33. Bertani LE, Bertani G: Genetics of $\mathbf{P 2}$ and related phages. Advances in Genetics 1971, 16:199-237.

34. Portelli R, Dodd IB, Xue Q, Egan JB: The late-expressed region of the temperate coliphage 186 genome. Virology 1998, 248: I I7-130.

35. Nilsson AS, Haggård-Ljungquist E: The P2-like bacteriophages. In The Bacteriophages Second edition. Edited by: Calendar R. New York: Oxford University Press; 2006:365-390.

36. Esposito D, Fitzmaurice WP, Benjamin RC, Goodman SD, Scocca IJ: The complete nucleotide sequence of bacteriophage HPI DNA. Nucleic Acids Research 1996, 24:2360-2368.

37. Nakayama K, Kanaya S, Ohnishi M, Terawaki Y, Hayashi T: The complete nucleotide sequence of $\mathrm{FCTX}$, a cytotoxin-converting phage of Pseudomonas aeruginosa: implications for phage evolution and horizontal gene transfer via bacteriophages. Molecular Microbiology 1999, 3 I:399-4I 9.

38. Kapfhammer D, Blass J, Evers S, Reidl J: Vibrio cholerae phage K 139: complete genome sequence and comparative genomics of related phages. Journal of Bacteriology 2002, I 84:6592-660I.

39. Campoy S, Aranda J, Alvarez G, Barbe J, Llagostera M: Isolation and sequencing of a temperate transducing phage for Pasteurella multocida. Applied \& Environmental Microbiology 2006, 72:3I54-3I60.

40. Beilstein F, Dreiseikelmann B: Temperate bacteriophage FO I 8P from an Aeromonas media isolate: characterization and complete genome sequence. Virology 2008, 373:25-29.

4I. Chibani-Chennoufi S, Dillmann ML, Marvin-Guy L, Rami-Shojaei S, Brüssow H: Lactobacillus plantarum bacteriophage LP65: a new member of the SPOI-like genus of the family Myoviridae. Journal of Bacteriology 2004, 186:7069-7083.

42. Uchiyama J, Rashel M, Maeda Y, Takemura I, Sugihara S, Akechi K, Muraoka A, Wakiguchi H, Matsuzaki S: Isolation and characterization of a novel Enterococcus faecalis bacteriophage fEF24C as a therapeutic candidate. FEMS Microbiology Letters 2008, 278:200-206.

43. Uchiyama J, Rashel M, Takemura I, Wakiguchi H, Matsuzaki S: In silico and in vivo evaluation of bacteriophage fEF24C, a candi- 
date for treatment of Enterococcus faecalis infections. Applied \& Environmental Microbiology 2008, 74:4|49-4I63.

44. Klumpp J, Dorscht J, Lurz R, Bielmann R, Wieland M, Zimmer M, Calendar R, Loessner MJ: The terminally redundant, nonpermuted genome of Listeria bacteriophage A5II: a model for the SPOI-like myoviruses of gram-positive bacteria. Journal of Bacteriology 2008, 190:5753-5765.

45. Allan BJ, Davies P, Carstens EB, Kropinski AM: Characterization of the genome of Pseudomonas aeruginosa bacteriophage phi PLS27 with particular reference to the ends of the DNA. Journal of Virology 1989, 63:1587-1594.

46. Perkus ME, Shub DA: Mapping the genes in the terminal redundancy of bacteriophage SPOI with restriction endonucleases. Journal of Virology 1985, 56:40-48.

47. Parker ML, Ralston EJ, Eiserling FA: Bacteriophage SPOI structure and morphogenesis. II. Head structure and DNA size. Journal of Virology 1983, 46:250-259.

48. Parker ML, Eiserling FA: Bacteriophage SPOI structure and morphogenesis. I. Tail structure and length regulation. Journal of Virology 1983, 46:239-249.

49. Dinsdale EA, Edwards RA, Hall D, Angly F, Breitbart M, Brulc JM, FurIan M, Desnues C, Haynes M, Li L, McDaniel L, Moran MA, Nelson KE, Nilsson C, Olson R, Paul J, Brito BR, Ruan Y, Swan BK, Stevens R, Valentine DL, Thurber RV, Wegley L, White BA, Rohwer F: Functional metagenomic profiling of nine biomes. Nature 2008 452:629-632.

50. Serwer P: Evolution and the complexity of bacteriophages. Virol J 2007, 4:30.

5I. Millard A, Clokie MRJ, Shub DA, Mann NH: Genetic organization of the psbAD region in phages infecting marine Synechococcus strains. Proceedings of the National Academy of Sciences of the United States of America 2004, I 01 :27.

52. Clokie MR, Shan J, Bailey S, Jia Y, Krisch HM, West S, Mann NH, Clokie MRJ, Shan J, Bailey S, Jia Y, Krisch HM, West S, Mann NH: Transcription of a 'photosynthetic' T4-type phage during infection of a marine cyanobacterium. Environmental Microbiology 2006, 8:827-835.

53. Stewart CR, Houtz JE, Smith A, Ford M, Peebles C, Casjens SR, et al.: The genome of Bacillus subtilis bacteriophage SPOI. 17th Evergreen International Phage Biology Meeting, Evergreen Olympia, WA, August 12-17. 2007.

54. Duda RL, Hendrix RW, Huang WM, Conway JF: Shared architecture of bacteriophage SPOI and herpesvirus capsids [erratum appears in Curr Biol. 2006 Feb 21;16(4):440]. Current Biology 2006, 16:RII-RI3

55. Kwan T, Liu J, DuBow M, Gros P, Pelletier J: The complete genomes and proteomes of 27 Staphylococcus aureus bacteriophages. Proceedings of the National Academy of Sciences of the United States of America 2005, 102:5 174-5 I79.

56. Carlton RM, Noordman WH, Biswas B, de Meester ED, Loessner MJ: Bacteriophage PIOO for control of Listeria monocytogenes in foods: genome sequence, bioinformatic analyses, oral toxicity study, and application. Regulatory Toxicology \& Pharmacology 2005, 43:30I-3/2

57. Twort FW: An investigation on the nature of the ultramicroscopic viruses. Lancet 1915, 189:1241-1243.

58. Summer EJ, Gonzalez CF, Carlisle T, Mebane LM, Cass AM, Savva CG LiPuma J, Young R: Burkholderia cenocepacia phage BcepMu and a family of Mu-like phages encoding potential pathogenesis factors. Journal of Molecular Biology 2004, 340:49-65.

59. Braid MD, Silhavy JL, Kitts CL, Cano RJ, Howe MM: Complete genomic sequence of bacteriophage B3, a Mu-like phage of Pseudomonas aeruginosa. Journal of Bacteriology 2004, I 86:6560-6574.

60. Wang PW, Chu L, Guttman DS: Complete sequence and evolutionary genomic analysis of the Pseudomonas aeruginosa transposable bacteriophage D3 I I 2. Journal of Bacteriology 2004 186:400-410.

6I. Gill GS, Hull RC, Curtiss R IIIrd: Mutator bacteriophage DI 08 and its DNA: an electron microscopic characterization. Journal of Virology 1981, 37:420-430.

62. Canchaya C, Proux C, Fournous G, Bruttin A, Brüssow H: Prophage genomics. Microbiology \& Molecular Biology Reviews 2003 67:238-276.
63. Fouts DE: Phage Finder: automated identification and classification of prophage regions in complete bacterial genome sequences. Nucleic Acids Research 2006, 34:5839-585I.

64. Morgan G], Hatfull GF, Casjens S, Hendrix RW: Bacteriophage Mu genome sequence: analysis and comparison with Mu-like prophages in Haemophilus, Neisseria and Deinococcus. Journal of Molecular Biology 2002, 3 I 7:337-359.

65. Andres S, Wiezer A, Bendfeldt H, Waschkowitz T, Toeche-Mittler C, Daniel R: Insights into the genome of the enteric bacterium Escherichia blattae: cobalamin (BI2) biosynthesis, BI2dependent reactions, and inactivation of the gene region encoding B I 2-dependent glycerol dehydratase by a new mulike prophage. Journal of Molecular Microbiology \& Biotechnology 2004, 8: $150-168$.

66. Saariaho AH, Lamberg A, Elo S, Savilahti H: Functional comparison of the transposition core machineries of phage $\mathrm{Mu}$ and $\mathrm{Hae}-$ mophilus influenzae Mu-like prophage Hin-Mu reveals interchangeable components. Virology 2005, 331:6-19.

67. Lobocka MB, Rose DJ, Plunkett G III, Rusin M, Samojedny A, Lehnherr H, Yarmolinsky MB, Blattner FR: Genome of bacteriophage PI. Journal of Bacteriology 2004, I 86:7032-7068.

68. Summer EJ, Gonzalez CF, Bomer M, Carlile T, Morrison W, Embry A, Kucherka AM, Lee J, Mebane L, Morrison WC, Mark L, King MD, LiPuma MJ, Vidaver AK, Young R: Divergence and mosaicism among virulent soil phages of the Burkholderia cepacia complex. Journal of Bacteriology 2006, I88:255-268.

69. Inoue Y, Matsuura T, Ohara T, Azegami K: Sequence analysis of the genome of OP2, a lytic bacteriophage of Xanthomonas oryzae pv. oryzae. Journal of General Plant Pathology 2006, 72:104-110.

70. Summer EJ, Berry J, Tran TA, Niu L, Struck DK, Young R: Rz/Rz I lysis gene equivalents in phages of Gram-negative hosts. Journal of Molecular Biology 2007, 373: 1098-III 2

7I. Casjens SR, Gilcrease EB, Winn-Stapley DA, Schicklmaier $P$, Schmieger H, Pedulla ML, Ford ME, Houtz JM, Hatfull GF, Hendrix RW: The generalized transducing Salmonella bacteriophage ESI8: complete genome sequence and DNA packaging strategy. Journal of Bacteriology 2005, 187: 1091-I 104.

72. Langley R, Kenna DT, Vandamme P, Ure R, Govan JR: Lysogeny and bacteriophage host range within the Burkholderia cepacia complex. Journal of Medical Microbiology 2003, 52:483-490.

73. Villegas A, She YM, Kropinski AM, Lingohr EJ, Mazzocco A, Ojha S, Waddell TE, Ackermann HW, Moyles DM, Ahmed R, Johnson RP: The genome and proteome of a virulent Escherichia coli O 157:H7 bacteriophage closely resembling Salmonella phage Felix OI. Virology Journal 2009, 6:4I.

74. Lehman SM, Kropinski AM, Castle AJ, Svircev AM: Complete genome of the broad-host-range Erwinia amylovora phage fEa2I-4 and its relationship to Salmonella phage felix 01 . Applied \& Environmental Microbiology 2009, 75:2139-2147.

75. Mobberley JM, Authement RN, Segall AM, Paul JH: The temperate marine phage fHAP-I of Halomonas aquamarina possesses a linear plasmid-like prophage genome. J Virol 2008, 82:6618-6630.

76. Oakey HJ, Cullen BR, Owens L, Oakey HJ, Cullen BR, Owens L: The complete nucleotide sequence of the Vibrio harveyi bacteriophage VHML. Journal of Applied Microbiology 2002, 93:1089- 1098.

77. Oakey HJ, Owens L, Oakey HJ, Owens L: A new bacteriophage, VHML, isolated from a toxin-producing strain of Vibrio harveyi in tropical Australia. Journal of Applied Microbiology 2000, 89:702-709.

78. Mobberley JM, Authement RN, Segall AM, Paul JH: The temperate marine phage FHAP-I of Halomonas aquamarina possesses a linear plasmid-like prophage genome. Journal of Virology 2008, 82:66|8-6630.

79. Ackermann H-W: $\mathbf{5 5 0 0}$ Phages examined in the electron microscope. Archives of Virology 2007, 152:227-243.

80. Hatfull GF, Pedulla ML, Jacobs-Sera D, Cichon PM, Foley A, Ford ME, Gonda RM, Houtz JM, Hryckowian AJ, Kelchner VA, Namburi S, Pajcini KV, Popovich MG, Schleicher DT, Simanek BZ, Smith AL, Zdanowicz GM, Kumar V, Peebles CL, Jacobs WR Jr, Lawrence JG, Hendrix RW: Exploring the mycobacteriophage metaproteome: phage genomics as an educational platform. PLOS Genetics 2006, 2:e92.

8I. Pedulla ML, Ford ME, Houtz JM, Karthikeyan T, Wadsworth C, Lewis JA, Jacobs-Sera D, Falbo J, Gross J, Pannunzio NR, Brucker W, Kumar 
V, Kandasamy J, Keenan L, Bardarov S, Kriakov J, Lawrence JG, Jacobs WR Jr, Hendrix RW, Hatfull GF: Origins of highly mosaic mycobacteriophage genomes. Cell 2003, II3:171-182.

82. Mayer MJ, Narbad A, Gasson MJ: Molecular characterization of a Clostridium difficile bacteriophage and its cloned biologically active endolysin. Journal of Bacteriology 2008, 190:6734-6740.

83. Goh S, Ong PF, Song KP, Riley TV, Chang BJ: The complete genome sequence of Clostridium difficile phage $\mathrm{fC} 2$ and comparisons to fCDII 9 and inducible prophages of CD630. Microbiology 2007, 153:676-685.

84. Govind R, Fralick JA, Rolfe RD: Genomic organization and molecular characterization of Clostridium difficile bacteriophage FCDI I 9. Journal of Bacteriology 2006, 188:2568-2577.

85. Goh S, Riley TV, Chang BJ: Isolation and characterization of temperate bacteriophages of Clostridium difficile. Appl Environ Microbiol 2005, 7I: 1079-1083.

86. Narasimhan G, Bu C, Gao Y, Wang X, Xu N, Mathee K: Mining protein sequences for motifs. Journal of Computational Biology 2002, 9:707-720

87. Mesyanzhinov VV, Robben J, Grymonprez B, Kostyuchenko VA Bourkaltseva MV, Sykilinda NN, Krylov VN, Volckaert G: The genome of bacteriophage phiKZ of Pseudomonas aeruginosa. Journal of Molecular Biology 2002, 3 17: I- 19.

88. Hertveldt K, Lavigne R, Pleteneva E, Sernova N, Kurochkina L, Korchevskii R, Robben J, Mesyanzhinov V, Krylov VN, Volckaert G: Genome comparison of Pseudomonas aeruginosa large phages. Journal of Molecular Biology 2005, 354:536-545.

89. Krylov VN, Dela Cruz DM, Hertveldt K, Ackermann H-W: "phiKZlike viruses", a proposed new genus of myovirus bacteriophages. Archives of Virology 2007, 152:1955-1959.

90. Thomas JA, Rolando MR, Carroll CA, Shen PS, Belnap DM, Weintraub ST, Serwer P, Hardies SC: Characterization of Pseudomonas chlororaphis myovirus 20 Ivarphi2-I via genomic sequencing, mass spectrometry, and electron microscopy. Virology 2008, 376:330-338.

91. Holloway BW, Egan JB, Monk M: Lysogeny in Pseudomonas aeruginosa. Australian Journal of Experimental Biology 1960, 38:32I-330.

92. Krylov VN, Tolmachova TO, Akhverdian VZ: DNA homology in species of bacteriophages active on Pseudomonas aeruginosa. Archives of Virology 1993, 131:|41-151.

93. Bergan T: A new bacteriophage typing set for Pseudomonas aeruginosa I. Selection procedure. Acta Pathologica et Microbiologica Scandinavica B 1972, 80: I 17-180.

94. Lindberg RB, Latta RL: Phage typing of Pseudomonas aeruginosa: clinical and epidemiological considerations. Journal of Infectious Diseases 1974, 130:S33-S43

95. Ackermann H-W, Cartier C, Slopek S, Vieu J-F: Morphology of Pseudomonas aeruginosa typing phages of the Lindberg set. Annales de l'Institut Pasteur/Virologie 1 988, 139:389-404.

96. Van Twest R, Kropinski AM: Bacteriophage enrichment from water and soil. Methods in Molecular Biology 2009, 50 I: I5-2I.

97. Kwan T, Liu J, DuBow M, Gros P, Pelletier J, Kwan T, Liu J, Dubow M, Gros P, Pelletier J: Comparative genomic analysis of 18 Pseudomonas aeruginosa bacteriophages. Journal of Bacteriology 2006, 188: I I84-II87.

98. Liu J, Dehbi M, Moeck G, Arhin F, Bauda P, Bergeron D, Callejo M, Ferretti V, Ha N, Kwan T, McCarty J, Srikumar R, Williams D, Wu J], Gros P, Pelletier J, DuBow M: Antimicrobial drug discovery through bacteriophage genomics. Nature Biotechnology 2004, 22: $|85-19|$.

99. Lima-Mendez G, van HJ, Toussaint A, Leplae R: Reticulate representation of evolutionary and functional relationships between phage genomes. Mol Biol Evol 2008, 25:762-777.

100. Rohwer F, Edwards R: The Phage Proteomic Tree: a genomebased taxonomy for phage. Journal of Bacteriology 2002, I 84:4529-4535.

101. Budzik JM, Rosche WA, Rietsch A, O'Toole GA: Isolation and characterization of a generalized transducing phage for Pseudomonas aeruginosa strains PAOI and PA 14. Journal of Bacteriology 2004, 1 86:3270-3273.

102. Pedulla ML, Lewis JA, Hendrickson HL, Ford ME, Houtz JM, Peebles CL, Lawrence JG, Hatfull GF, Hendrix RW: Bacteriophage G: analysis of a bacterium-sized phage genome. Proceeding of the $103 \mathrm{rd}$ Annual Meeting of the American Society for Microbiology, Washington, DC 2003
103. Sullivan MB, Coleman ML, Weigele P, Rohwer F, Chisholm SW, Sullivan MB, Coleman ML, Weigele P, Rohwer F, Chisholm SW: Three Prochlorococcus cyanophage genomes: signature features and ecological interpretations. Plos Biology 2005, 3: e 44.

104. Mann NH, Clokie MR, Millard A, Cook A, Wilson WH, Wheatley PJ, Letarov A, Krisch HM: The genome of S-PM2, a "photosynthetic" T4-type bacteriophage that infects marine Synechococcus strains. Journal of Bacteriology 2005, 187:3188-3200.

105. Mann NH: The third age of phage. Plos Biology 2005, 3:el82.

106. Weigele PR, Pope WH, Pedulla ML, Houtz JM, Smith AL, Conway JF, King J, Hatfull GF, Lawrence JG, Hendrix RW: Genomic and structural analysis of Syn9, a cyanophage infecting marine Prochlorococcus and Synechococcus. Environmental Microbiology 2007, 9:1675-1695.

107. Lavigne R, Seto D, Mahadevan O, Ackermann H-W, Kropinski AM: Unifying classical and molecular taxonomic classification: analysis of the Podoviridae using BLASTP-based tools. Research in Microbiology 2008, 159:406-4I4.
Publish with Biomed Central and every scientist can read your work free of charge

"BioMed Central will be the most significant development for disseminating the results of biomedical research in our lifetime."

Sir Paul Nurse, Cancer Research UK

Your research papers will be:

- available free of charge to the entire biomedical community

- peer reviewed and published immediately upon acceptance

- cited in PubMed and archived on PubMed Central

- yours - you keep the copyright
BioMedcentral 